\title{
The use of blended raw whole egg and albumin as deer repellents at feeding stations
}

\author{
DAVID A. JOHNSON \\ Ohio University, Athens, Ohio
}

\begin{abstract}
The application of blended fresh whole egg to ears of corn provided an effective repellent to consumption by white-tailed deer at feeding stations. Albumin applied in a similar manner was also highly effective. Neither rain nor snow significantly reduced the repellent properties of either substance.
\end{abstract}

In the fall of 1976, my family and I moved into a rural area of Athens County in Southeastern Ohio. The following winter, 1976-77, was one of the coldest and snowiest on record. It was not long before I discovered that the area was inhabited by a population of white-tailed deer exceeding 25/square mile.

Besides animal behavior, one of my interests is the rearing of various evergreen shrubs. During the winter of 1976-77, I discovered the problems browsing deer can present to the homeowner, particularly during long periods when 6 in. or more of snow are on the ground.

For the past 8 winters, I have been studying deer behavior in my backyard among my pines, yews, rhododendrons, and other assorted shrubs. The following paper presents data from my attempts to find a substance that would repel deer sufficiently to protect my shrubbery from excessive browse damage.

Over the years, people have tried a variety of mechanical means to curtail deer-browse damage. Electric fences, high woven-wire fences, or even chicken-wire cages have been used with considerable success, but they are expensive and unsightly, and eventually iron oxides from the rusting fence can damage foliage. Some people in this area wrap their shrubs with burlap from ground level to a height of $6 \mathrm{ft}$. These methods work, but they are timeconsuming. Moreover, the purpose of most landscaping is not to provide a place to hang burlap during the drab winter months. There are also elastic polypropylene mesh stockings that can be fitted over the apical buds of conifers. These stockings are useful for protecting plantations of small pines, but in a few years, the pines produce hundreds of lateral leaders that are tasty to the deer. Aluminum pie pans or other wind-activated devices quickly lose their repellent properties as deer become habituated

\footnotetext{
Corn for this study was purchased by a grant from the Ohio University Research Foundation. Apples were generously donated by John Gillogly of Gillogly Orchards, Albany, Ohio. The author's mailing address is: Department of Psychology, Porter Hall, Ohio University, Athens, OH 45701-2979.
}

to their presence. It is even common for deer to passively browse within $10 \mathrm{ft}$ of a barking, tethered dog. Turn the dog loose, and the deer will be kept at bay when the dog is awake, but one must be prepared for barking dogs at all hours of the night.

A number of repellent substances have also been tried (Allen, Gustafson, Mikels, Miller, \& Neogi, 1984). Lion manure is reputed to have some effect. Human hair also has been mentioned. Research clearly shows that a few substances work. Putrescent whole-egg solids (Stockdale, 1981) and selenium (Allen et al., 1984) have both been field-tested and have considerably reduced browse damage.

My first attempt to protect my shrubbery was to provide alternative feeding stations using cob corn as a food source. I have continued this practice over the years because it succeeds in regularly attracting deer during daylight hours to the feeding post, where I can observe, photograph, or videotape them. Within the first week, however, I discovered that I was attracting 20-30 deer per evening and only whetting their appetites with the 75-100 ears of corn that I fed to them.

By chance, I saw a commercial on television describing the fact that Weyerhaeuser Company was using an egg product in research to protect its coniferous seedlings from browse damage. The product was in the testing stage and not yet available. Although I inquired, it was several years before I discovered that the product was called BGR (Big Game Repellent) and marketed by the McLaughlin, Gormby, King Company in cooperation with Weyerhaeuser. BGR's primary ingredient is putrescent whole-egg solids (37\%). The remaining inert vehicle allows the slurry to be spray-applied to plant foliage.

In the meantime, I was in need of a repellent. I decided to simply blend six eggs, shell and all, for my first attempt. The feeding station provided an excellent opportunity to determine whether the application of blended eggs to an ear of corn would prevent consumption. I also could gauge how much of the repellent needed to be applied, and for how long under certain weather conditions an application would last. I also could observe the reactions of the deer to the odor of eggs. 


\section{METHOD}

\section{Study Area and Subjects}

White-tailed deer (Odocoileus virginianus borealus) in the present study occupy a range of about 1,000 acres. Ecologically, the area is about $50 \%$ mature oak-hickory forest, $25 \%$ scrubland about 15 years into reversion, $10 \%$ corn or soybean fields, and $15 \%$ dense white-pine thickets. Reverting acreage and pine thickets have a heavy understory of greenbriar, honeysuckle, and multiflora rose. These areas provide a haven for deer, as they are nearly impenetrable to humans. Most of the deer frequenting the study area range within 1 mile of my yard. In 7 of the last 8 years, they have remained dispersed throughout their range. During the winter of 1977-78, they formed a 50-acre yard adjacent to my house. Hunting in the study area results in some reduction in the population. About 1 of every 4-5 animals fails to reappear after deer season, which is usually held during the 1st week of December. Observations were made in a 4-acre area surrounding my house. This area is a partially open knoll on a long eastwest ridge. The ridge lies between two large forested valleys to the north and south of the study area.

The number and demographics of the population change in minor ways from year to year. The number of deer observed in any particular year has varied from 20 to 35 across years. Mature buck deer (21/2 years old or older) visit the yard only rarely during the evening observation period except during the rutt, when nightly appearances are typical. Most deer approach the vicinity in small family groups of 3-7. The mean number of deer across years that regularly use the yard to feed is 21 . In an average year, 8 mature doe, 11 fawn, and two 11/2 year-old buck deer regularly feed at the feeding posts.

During the late fall and early winter (mid-October until January 1) of each year since 1976, free-ranging white-tailed deer were encouraged to frequent my yard to feed. During this time, two 5-gal buckets of apples and one 5-gal bucket of field corn were placed daily at specific feeding sites within 25-50 ft of the house. Apples were scattered about the ground, and corn was placed on specific low-level branches of indigenous rosebud trees. This was accomplished by breaking a branch about $1 / 4$-in. in diameter, and sharpening it for easy insertion into the pithy portion of the corn cob. This procedure did not immediately result in heavy feeding in the observation area, but with the decreased availability of herbaceous foods in November, deer began to regularly visit the yard, although after darkness. By December, deer began to arrive in the yard about 5:00 p.m. to ensure that some of this food would be available to them. By January 1, apples were depleted, but deer had developed a nightly habit of visiting the yard for corn, beginning about 45 min before dark. They learned the usual locations of the corn and if, for some reason, I was late in baiting the feeding post, the deer checked every branch where corn was usually placed. Six 75-W spotlights were sometimes used to flood the feeding posts. During November and December, these lights were periodically turned on and, by late December, deer were not frightened by artificial lighting. Thus, night viewing was possible, in addition to the $45 \mathrm{~min}$ before dark when deer were typically present. Observation and photography was conducted from behind double-pane insulated windows, which create a mirror appearance during daylight since the outside is brighter than the inside. At night, observation was from a darkened room, so that the observer was not visible to the deer. Although these deer were not timid about approaching the house, they certainly were not tame. Any attempt by the researcher to move outside produced instant flight on the part of the deer.

\section{Procedure}

Observations were recorded between January 1 and March 1 during the winter months from 1977 to 1985 . Eight to 10 tests were conducted each year. Between test sessions, untreated corn was provided. On all test nights, 50 untreated ears of corn were placed at five feeding posts. One treated ear was placed at each feeding post. A small string was inconspicuously tied to the branch holding the treated ear (about $1 \mathbf{f t}$ from the ear). If the treated ear of corn was not eaten on Day 1 , it was moved to another branch at the same feeding post, and 10 new untreated ears were placed on neighboring branches. (Treated ears had to be collected each morning to prevent consumption by blue jays and other birds.)
Observations were made on general behavioral reaction to the treated ear, whether it was consumed or not, and on how many successive days a treated ear retained its potency. Data also were grouped to determine the impact of snow or rain on deterrent efficiency. In the winters of 1977-82, whole-egg solids were applied as repellents. During the winter of 1984-85, albumin paste was applied instead of raw blended egg.

The whole-egg slurry was prepared by mixing whole eggs and water (50\% each) for $5 \mathrm{sec}$ in an Oster blender. A $1 / 2$-in. paint brush was then used to liberally apply the slurry in three lengthwise stripes along the entire length of the cob of corn. Albumin was prepared by thoroughly mixing $10 \%$ albumin powder and $90 \%$ water. The thin albumin glue was then applied to each test cob of corn in a manner identical to that described above.

\section{RESULTS}

Deer appear to distinctly dislike the smell of either fresh blended whole egg or albumin. When snow is deep and naturally occurring food is scarce, deer repeatedly sniff or test the treated ear. Seldom, however, do their heads come within $1 \mathrm{ft}$ of the treated ear. Frequently, they curl their upper lips in a response reminiscent of the Flehmen response to female urine. Sometimes, they jump back 2-3 $\mathrm{ft}$ after smelling a treated ear.

Data from 60 test nights are reported here for blended raw-egg treatments. Of 3,000 untreated ears, all but 56 were consumed during Night 1 . It is interesting to note that 21 of the 56 uneaten ears were adjacent to a treated ear (within $1 \mathrm{ft}$ ). Of the 300 treated ears, none were eaten during Night $1 ; 12$ were nibbled but were less than $10 \%$ consumed. In spite of the fact that treated and unconsumed ears were removed every morning, the blue jays and cardinals, not to mention an occasional crow, frequently managed to peck a few grains from the test ears. This loss became progressively more severe, such that by Day 6, testing had to be discontinued. Nevertheless, data demonstrate that although the birds are not repelled even on Day 1 , deer clearly avoid eating even after 6 days. Of the 56 untreated ears that were not consumed on Day 1, all 56 were consumed on Day 2. For treated ears, however, repellent properties protected all 300 treated ears until Day 6 of testing. It was apparent that, had birds not disturbed the treated ears, deer would have displayed strong aversion well beyond Day 6. Data from 8 rain days show that 8 of 12 cases of incomplete consumption of treated ears occurred on days when rain had a chance to dilute or weaken the concentration of egg remaining on the corn. Accumulation of snow on the ear was no impediment to deterrence, perhaps because the underside of the treated corn was usually still unobstructed.

During the winters of 1983-84 and 1984-85, 16 test nights were conducted using a thin albumin paste instead of blended whole-egg solids. During these tests, all untreated (800) ears of corn were consumed. Only 2 of the 150 test ears showed any signs of consumption over days of testing, and these 2 were less than $10 \%$ consumed. None of the albumin-treated ears were consumed after rains. The behavioral reaction to albumin was even more noticeable than that to blended whole eggs. Most animals 
would shake their heads and jump backward, much as humans would when smelling ammonia, although neither the egg or the albumin had much of a noticeable odor to humans.

Behavioral observations indicated that during test nights, as untreated ears were consumed, treated ears were tested more and more frequently. On a typical evening in February, most untreated ears would be consumed within 45 min after deer arrived in the yard. Test ears then became the center of attention. Each deer usually approached every untreated ear 1-3 times before giving up and leaving the yard. It is not uncommon, then, for a test ear to be approached, smelled, and rejected 30-50 times per night.

\section{DISCUSSION}

It is clear that whole-egg slurries or egg-albumin paste effectively deter consumption of corn at feeding posts for up to 6 days. Moreover, there is every indication that the repellent properties of egg are still strong at the end of this period. These data suggest that whole egg or egg albumin may serve as effective browse deterrents. These data also suggest that the deterrence found in BGR may be related to its albumin content rather than its putrescence. Whole-egg slurries can be easily concocted for $\$ .50$ from almost any refrigerator. BGR, which has worked reasonably well (Stockdale, 1981), is not readily available in most areas, nor are most homeowners even aware of it. Clearly, whole-egg solids have potential for repellent for the average homeowner who wishes, perhaps, to protect his shrubbery. In the next series of experiments, I will assess the efficiency of whole egg and egg albumin in reducing browse damage when applied to the foliage of shrubbery. So far the results look very promising.

\section{REFERENCES}

Allen, G. G., Gustafson, D. I., Mikels, R. A., Miller, J. M., \& NEOGI, S. (1984). Reduction of deer browsing of douglas-fir seedlings by quadravalent selenium. Forest Ecology \& Management, 7, 163-181. Stockdale, M. (1981). Nipped in the bud. Tennessee Wildlife Magazine, 13, 20-21.

(Manuscript received for publication September 27, 1985). 